\title{
Do Continuous Flow LVADS Improve Diastolic Dysfunction?
}

\author{
Nandini Nair ${ }^{1,2 *}$, Sudhir Thotakura1, Enrique Gongora ${ }^{3}$ \\ ${ }^{1}$ Scott and White Memorial Hospital and TAMHCS College of Medicine, Temple, TX, USA \\ ${ }^{2}$ Providence Spokane Heart Institute/Sacred Heart Medical Center, Spokane, WA, USA \\ ${ }^{3}$ Memorial Cardiac and Vascular Institute, Hollywood, FL, USA \\ Email: " nandini.nair@gmail.com
}

Received 9 May 2014; revised 10 June 2014; accepted 10 July 2014

Copyright (C) 2014 by authors and Scientific Research Publishing Inc.

This work is licensed under the Creative Commons Attribution International License (CC BY). http://creativecommons.org/licenses/by/4.0/

(c) $\underset{\mathrm{EY}}{\mathrm{B}}$ Open Access

\section{Abstract}

Background: Ventricular assist devices are now used as a bridge to recovery/decision/transplant or as destination therapy in end-stage heart failure. Continued improvements in technology and pump design have made implantation an easier process with reduced operative risks and pumprelated adverse events. Considering the beneficial effects of these devices in the clinical setting, it seemed logical to address the long-term effect of the continuous flow pumps on diastolic dysfunction. Methods: This study addresses the effect of HeartMate II $^{\mathrm{TM}}$ (HMII) support for $284+/-97$ days on echocardiographic parameters of diastolic function. Data from fifteen patients was retrospectively studied status post left ventricular assist device (LVAD) implantation. The data at approximately 1-year post implantation was compared with that obtained prior to implantation. Statistical analyses were performed using the Microsoft Excel Program/MSExcel Stats. Echocardiographic measurements were carried out in accordance with the American Society of Echocardiography guidelines. Results: Of all the echocardiographic parameters assessed only E/Ea and calculated left atrial pressure (LAP) showed a statistically significant decrease. Two parameters that showed a trend towards significance are Ea (septal) and global functional index $(p=0.05)$. Conclusions: Continuous Flow LVAD support appears to improve diastolic dysfunction. This study has limitations in that we used a single type of continuous flow device (HeartMate $\mathrm{II}^{\mathrm{TM}}$ ) and was conducted as a retrospective analysis. Further studies with larger populations and longer support are required to validate this finding.

\section{Keywords}

Continuous Flow Device, Diastolic Function, HeartMate II $^{\mathrm{TM}}$, Left Ventricular Assist Devise

\footnotetext{
*Corresponding author.
} 


\section{Introduction}

With increasing incidence of heart failure, left ventricular assist device (LVAD) therapy has evolved as an integral component of advanced heart failure care. Ventricular assist devices are now used as a bridge to recovery/decision/transplant or as destination therapy in end-stage heart failure [1]-[4]. Continued improvements in technology and pump design have made implantation easier with reduced operative risks and related adverse events. The newer axial flow pumps have better durability and fewer moving parts. Their smaller size makes them ideal for patients with a smaller body habitus. Continuous flow pumps have also been shown to prolong and improve quality of life [5]-[7]. Considering the beneficial effects of these devices in the clinical setting, it seemed imperative to address the long-term effect of continuous flow pumps on diastolic function. This retrospective analysis addresses the effect of HeartMate II ${ }^{\mathrm{TM}}$ (HMII) support for 284+/-97 days on echocardiographic parameters of diastolic function.

Diastolic dysfunction can be defined as impaired ventricular filling secondary to abnormalities in relaxation, high left atrial pressures, poor ventricular compliance and defective atrial contractile properties. This conglomerate of abnormalities result in increased pressure transmitted back into the lungs and heart failure symptoms. Heart failure with preserved ejection fraction (HFpEF) carries a similar magnitude of morbidity and mortality as heart failure with reduced ejection fraction (HFrEF) [8]. Mitral annular velocities are favored in studies of left ventricular diastolic function because they are less load dependent than mitral inflow velocities. This can be explained by the mitral annulus motion essentially representing movements in the longitudinal axis.

Figure 1 shows the basic tissue Doppler recordings consisting of systolic velocity (Sa) and early diastolic velocity (Ea) waveforms which form the basic parameters for calculation of the global functional index (GFI). Ea is inversely correlated with the time constant of isovolumic relaxation (tau). Sa represents mitral annulus peak systolic velocity. The quantity E/(EaxSa) correlates strongly with LVEDP in patients with severe mitral regurgitation (MR) [9]. The GFI is obtained by multiplying (E/Ea) by 1/Sa. GFI therefore assumes significance in its ability to be a surrogate marker for left ventricular end diastolic pressure (LVEDP). Abnormal LVEDP is one of the first markers of diastolic dysfunction. Hence, GFI and the component parameters have been used in this study to assess the effects of mechanical circulatory support on diastolic dysfunction. Additionally left atrial pressure (LAP) derived by the formula E/Ea $\times 1.24+1.9$ as described by Nagueh et al. [10] has been studied pre and post LVAD implantation.

\section{Methods}

This study comprises a small group of patients with a single type of continuous flow devices (HeartMate IITM). Data from fifteen patients was retrospectively studied status post LVAD implantation. The data at approximately 1-year post implantation was compared with that obtained prior to implantation. This project was approved by the institutional review board at Scott and White Memorial Hospital, Temple, TX (protocol ID number 110460) Statistical analyses were performed using the Microsoft Excel Program/MSExcel Stats. The student's $t$ test and the Mann Whitney tests were performed on the data represented as the sample size was small The GFI and LAP was calculated as described elsewhere.

All echocardiographic examinations were performed in the ICAEL-certified cardiac ultrasound laboratory at Scott and White Hospital, Temple, TX, USA. Echocardiographic measurements were carried out in accordance with the American Society of Echocardiography guidelines [11] [12].

\section{Results}

Table 1 shows the baseline characteristics of study patients used in the analyses. Sixty percent of the patients were bridge to transplant and the remaining $40 \%$ were implanted as destination therapy. The patient population was by default $94 \%$ male and $6 \%$ female. Approximately $50 \%$ patients had hypertension, diabetes and history of tobacco use. The etiology of cardiomyopathy was ischemic in $60 \%$ of the patients. Average age of implantation was 52 years.

Table 2 shows all the echocardiographic parameters analyzed 1-month pre and 1-year status post LVAD implantation. The values represent mean $+/-$ standard deviation. Two parameters that showed a trend towards significance are Ea (septal) and GFI. However, the latter two parameters did not achieve statistical significance in this examination Figures 2(a)-(d) are graphic representations of E/Ea, GFI, Ea and left atrial pres- 


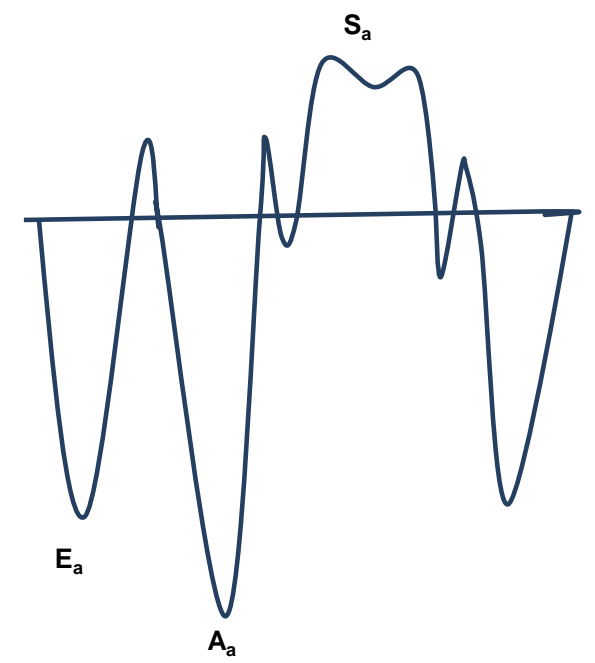

Figure 1. Basic tissue Doppler recording.

Table 1. Baseline characteristics of patients.

\begin{tabular}{cc}
\hline Characteristic & Percentage expressed in parentheses \\
Male & $14(94)$ \\
Female & $1(6)$ \\
Age at Implantation & $52 \pm 17$ \\
Ischemic & $9(60)$ \\
Non-Ischemic & $6(40)$ \\
Diabetes Mellitus (DM) & $7(47)$ \\
Hypertension & $8(54)$ \\
Length of Pump Support (LOPS) & $284 \pm 97$ \\
Bridge-to-Transplant (BTT) & $9(60)$ \\
Destination Therapy (DT) & $6(40)$ \\
History of Tobacco Use & $8(54)$ \\
\hline
\end{tabular}

Table 2. Effect of CF axial LVADS on tissue Doppler indices.

\begin{tabular}{cccc}
\hline Doppler Index & Pre-LVAD & Post-LVAD & $\mathrm{p}$ \\
\hline E & $91.72+/-29.6$ & $76.9+/-17.0$ & $\mathrm{p}=\mathrm{ns}$ \\
$\mathrm{A}$ & $49.5+/-16.2$ & $83.7+/-15.7$ & $\mathrm{p}=\mathrm{ns}$ \\
GFI & $6.5+/-6.7$ & $3.4+/-2.7$ & $\mathrm{p}=0.05^{*}$ \\
E/A & $1.6+/-0.7$ & $1.6+/-0.7$ & $\mathrm{p}=\mathrm{ns}$ \\
E/Ea & $25.4+/-14.9$ & $15.8+/-8.2$ & $\mathrm{p}<0.05^{* *}$ \\
Ea & $4.4+/-1.8$ & $5.6+/-2.1$ & $\mathrm{p}=0.05^{*}$ \\
DT & $160.1+/-71.6$ & $183.2+/-64.8$ & $\mathrm{p}=\mathrm{ns}$ \\
IVRT & $79.1+/-18.8$ & $84.4+/-19.6$ & $\mathrm{p}=\mathrm{ns}$ \\
LAVI & $47.7+/-40.1$ & $16.7+/-21.4$ & $\mathrm{p}=\mathrm{ns}$ \\
Vp & $44.8+/-5.8$ & $38.6+/-7.7$ & $\mathrm{p}=\mathrm{ns}$ \\
LAP & $34.5+/-19.2$ & $21.5+/-10.3$ & $\mathrm{p}<0.05^{* *}$ \\
E/Vp & $1.9+/-0.5$ & $1.9+/-0.3$ & $\mathrm{p}=\mathrm{ns}$ \\
\hline
\end{tabular}

${ }^{* *}$ statistically significant. DT: deceleration time. IVRT: isovolumic relaxation time. LAVI: left atrial volume index 


\section{E/Ea}

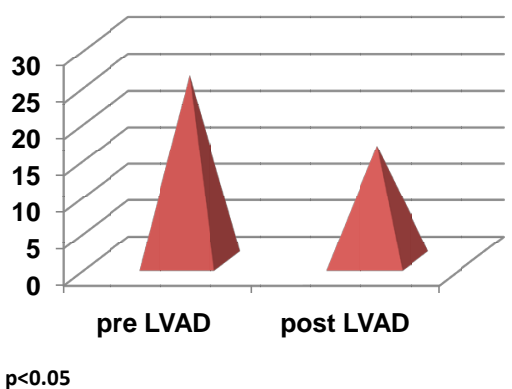

(a)

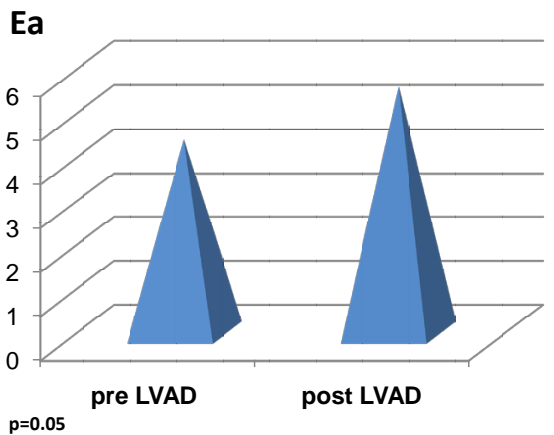

(c)

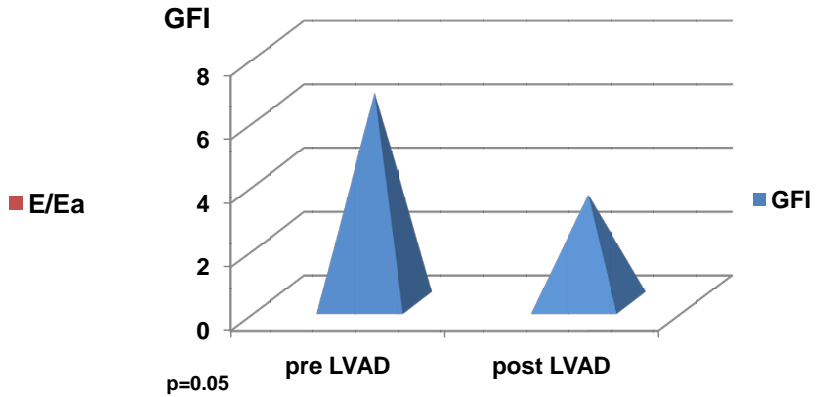

(b)

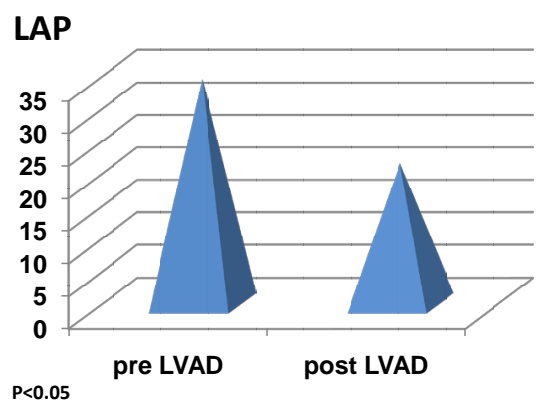

(d)

Figure 2. (a) Effect of CF-LVADS on E/Ea. (B) Effect of CF-LVADS on global functional index (GFI). (C) Effect of CF-LVADS on early diastolic velocity (Ea). (D) Effect of CF-LVADS on left atrial pressure (LAP).

sure respectively. The two parameters that attained statistical significance are $\mathrm{E} / \mathrm{Ea}$ and left atrial pressure, which was manually calculated using the formula published by Nagueh et al. [10]. Abnormal left atrial pressure is one of the earliest findings in diastolic dysfunction. The findings presented here therefore represent a positive trend towards improvement of diastolic dysfunction.

\section{Discussion}

The data presented in this study generates interest from the point of view of changes on myocardial structure and function by continuous flow pumps. Earlier studies with continuous flow devices have shown that they do not markedly improve diastolic function as compared to pulsatile pumps [13]. All echocardiographic parameters appeared to be unaltered in the continuous flow group [13]. This effect has been attributed to the fact that continuous flow devices are not able to recapitulate a physiological pattern of unloading. Unloading of the left ventricle by continuous-flow LVADs has been shown to derange the physiologic profile of myocardial bioenergetics as well as vascular hemodynamics as compared to the pulsatile LVADS. This was demonstrated in a bovinemodel study [14].

The precise effects of continuous flow LVADS on diastolic function is still not very clearly defined. As compared to pulsatile devices, the effect of these devices on diastolic dysfunction has been shown to be much less pronounced. However, in a prospective study of 80 patients pre-LVAD to 365 days post-LVAD placement, a statistically significant effect on ventricular unloading was noted very early (at 30 days of pump support) [15] [16]. Our study shows a statistically significant change in the E/Ea ratio pre and post LVAD. It should also be noted that these patients had highly abnormal values to start with (see Table 2) with 73\% in INTERMACS 1 and 27\% in INTERMACS 2 at implantation.

GFI incorporates E, Ea and Sa as mentioned above. The quantity E/EaxSa has been hypothesized to represent LVEDP [9]. Hence, it is interesting that LVAD support decreases GFI in this study. GFI does not achieve significance, but it tends towards it as shown in Table 2 and Figure 2(b). Similarly, Ea, the early diastolic velocity, tends towards significance as shown in Table 2 and Figure 2(c). Figure 2(d) and Table 2 shows the LAP pre 
and post ventricular assist device implantation. LAP appears to decrease in a statistically significant manner $(\mathrm{p}<$ $0.05)$.

In conclusion, continuous flow (CF)-LVAD support appears to improve diastolic dysfunction. Further studies with larger populations and longer support are required to validate this finding. Our study has several limitations in that we used a single type of CF-LVAD namely the HeartMate $\mathrm{II}^{\mathrm{TM}}$ and the analyses was retrospective. The study was also limited by the fact that all of the patients were either INTERMACS level 1 (73\%) or INTERMACS level 2 (27\%). The echocardiographic parameters shown in Table 2 demonstrate that at baseline the study population had higher grades of diastolic dysfunction bordering reversible/restrictive diastolic dysfunction. Therefore, a larger study, which includes patients with lower grades of diastolic dysfunction, may be useful in defining the kinetics of molecular remodeling, as higher degrees of remodeling may be refractory to the beneficial effects of ventricular unloading.

\section{References}

[1] Rose, E.A., Gelijns, A.C., Moskowitz, A.J., et al. (2001) Long-Term Use of a Left Ventricular Assist Device for End-Stage Heart Failure. New England Journal of Medicine, 345, 1435-1443. http://dx.doi.org/10.1056/NEJMoa012175

[2] Park, S.J., Tector, A., Piccioni, W., et al. (2005) Left Ventricular Assist Devices as Destination Therapy: A New Look at Survival. Journal of Thoracic and Cardiovascular Surgery, 129, 9-17. http://dx.doi.org/10.1016/j.jtcvs.2004.04.044

[3] Frazier, O.H., Rose, E.A., Oz, M.C., et al. (2001) Multicenter Clinical Evaluation of the HeartMate Vented Electric Left Ventricular Assist System in Patients Awaiting Heart Transplantation. Journal of Thoracic and Cardiovascular Surgery, 122, 1186-1195. http://dx.doi.org/10.1067/mtc.2001.118274

[4] Frazier, O.H., RoseE, A., Oz, M.C., et al. (2001) Multicenter Clinical Evaluation of the Heartmate; Vented Electric Left Ventricular Assist System in Patients Awaiting Heart Transplantation. The Journal of Heart and Lung Transplantation, 20, 201-202.

[5] Frazier, O.H., Myers, T.J., Westaby, S. and Gregoric I.D. (2004) Clinical Experience with an Implantable, Intracardiac, Continuous Flow Circulatory Support Device: Physiologic Implications and Their Relationship to Patient Selection. Annals of Thoracic Surgery, 77, 133-142. http://dx.doi.org/10.1016/S0003-4975(03)01321-3

[6] Miller, L.W., Pagani, F.D., Russell, S.D., et al. (2007) Use of a Continuous-Flow Device in Patients Awaiting Heart Transplantation. New England Journal of Medicine, 357, 885-896. http://dx.doi.org/10.1056/NEJMoa067758

[7] Pagani, F.D., Miller, L.W., Russell, S.D., et al. (2009) Extended Mechanical Circulatory Support with a Continuous-Flow Rotary Left Ventricular Assist Device. Journal of the American College of Cardiology, 54, 312-321. http://dx.doi.org/10.1016/j.jacc.2009.03.055

[8] Najjar, S.S. (2009) Heart Failure with Preserved Ejection Fraction: Failure to Preserve, Failure of Reserve, and Failure on the Compliance Curve. Journal of the American College of Cardiology, 54, 419-421. http://dx.doi.org/10.1016/j.jacc.2009.05.011

[9] Mornoş, C., Cozm, D., Petrescu, L., Ionac, A., Rusinaru, D. and Dragulescu, S.I. (2010) E/(EaxSa) Estimates Left Ventricular End-Diastolic Pressure in Patients with Severe Mitral Regurgitation. Journal of Heart Valve Disease, 19, 576-583.

[10] Nagueh, S.F., Middleton, K.J., Kopelen, H.A., Zoghbi, W.A. and Quinones, M.A. (1997) Doppler Tissue Imaging: A Noninvasive Technique for Evaluation of Left Ventricular Relaxation and Estimation of Filling Pressures. Journal of the American College of Cardiology, 30, 1527-1533.

[11] Nishimura, R.A., Housmans, P.R., Hatle, L.K. and Tajik, A.J. (1989) Assessment of Diastolic Function of the Heart: Background and Current Applications of Doppler Echocardiography. Part I. Physiologic and Pathophysiologic Features. Mayo Clinic Proceedings, 64, 71-81. http://dx.doi.org/10.1016/S0025-6196(12)65305-1

[12] Basnight, M.A., Gonzalez, M.S., Kershenovich, S.C. and Appleton, C.P. (1991) Pulmonary Venous Flow Velocity: Relation to Hemodynamics, Mitral Flow Velocity and Left Atrial Volume and Ejection Fraction. Journal of the American Society of Echocardiography, 4, 547-558. http://dx.doi.org/10.1016/S0894-7317(14)80213-7

[13] Kato T.S., Chokshi, A., Singh, P., et al. (2011) Effects of Continuous-Flow versus Pulsatile-Flow Left Ventricular Assist Devices on Myocardial Unloading and Remodeling. Circulation: Heart Failure, 4, 546-553. http://dx.doi.org/10.1161/CIRCHEARTFAILURE.111.962142

[14] Bartoli, C.R., Giridharan, G.A., Litwak, K.N., Sobieski, M., Prabhu, S.D., Slaughter, M.S. and, Koenig, S.C. (2010) Hemodynamic Responses to Continuous versus Pulsatile Mechanical Unloading of the Failing Left Ventricle. ASAIO Journal, 56, 410-416. http://dx.doi.org/10.1097/MAT.0b013e3181e7bf3c

[15] Wever-Pinzon, O., Stehlik, J., Kfoury, A.G., et al. (2012) Effects of Continuous-Flow Left Ventricular Assist Device 
Unloading on the Diastolic Function of the Failing Human Heart.[Abstract 19188] American Heart Association Scientific Sessions, Los Angeles. http://circ.ahajournals.org/cgi/content/meeting_abstract/126/21_MeetingAbstracts/A19188

[16] Drakos, S.G., Wever-Prinzon, O., Selzman, C.H., et al. (2013). Magnitude and Time Course of Changes Induced by Continuous-Flow Left Ventricular Assist Device Unloading in Chronic Heart Failure: Insights Into Cardiac Recovery. Journal of the American College of Cardiology, 61, 1985-1994. http://dx.doi.org/10.1016/j.jacc.2013.01.072 
Scientific Research Publishing (SCIRP) is one of the largest Open Access journal publishers. It is currently publishing more than 200 open access, online, peer-reviewed journals covering a wide range of academic disciplines. SCIRP serves the worldwide academic communities and contributes to the progress and application of science with its publication.

Other selected journals from SCIRP are listed as below. Submit your manuscript to us via either submit@scirp.org or Online Submission Portal.
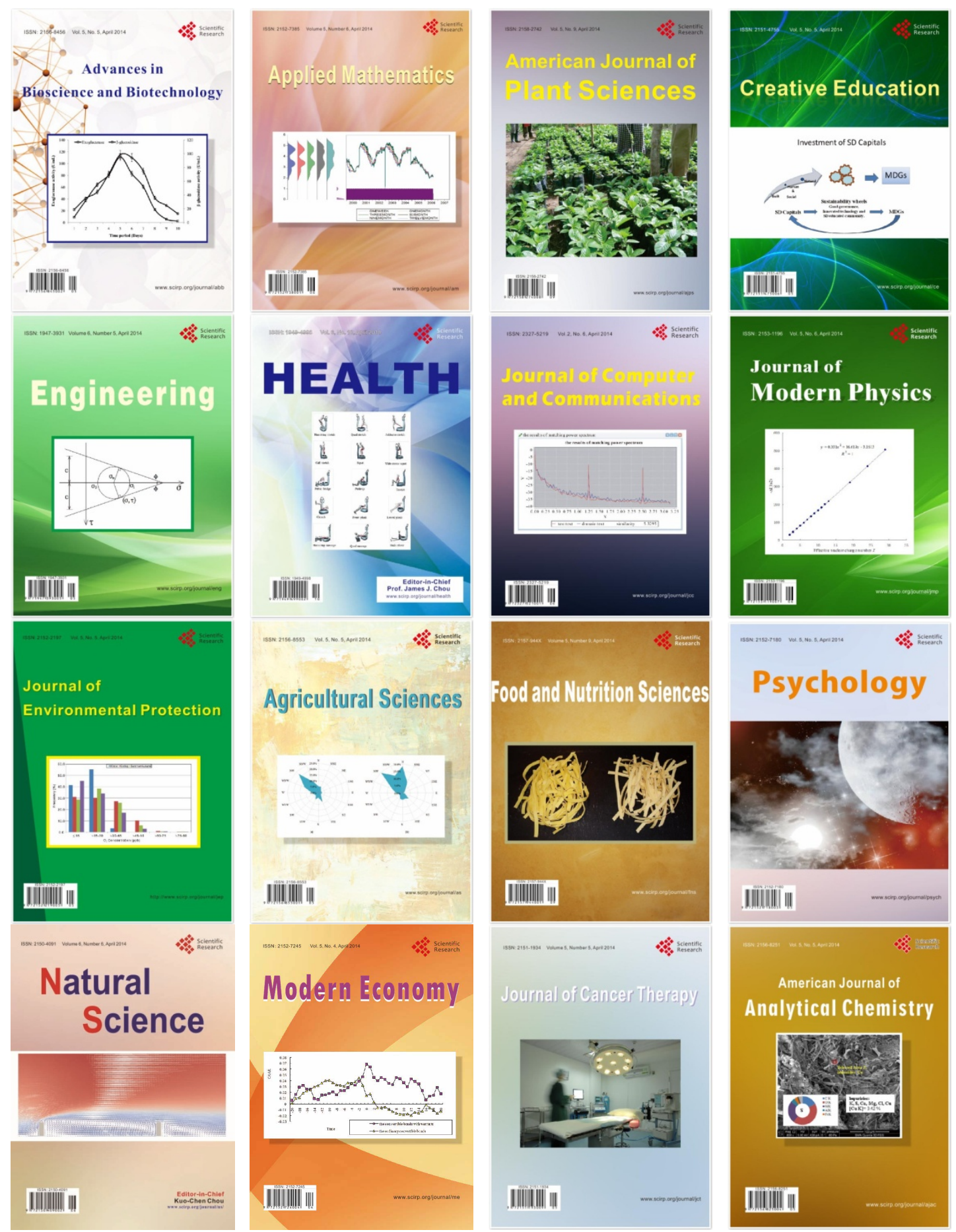